\title{
Content and structure of massive open online courses technologies in the context of trends in the organization teaching in higher education institutions
}

\author{
Tamara Asten, and Ekaterina Egorova* \\ Don State Technical University, 344002, Rostov-on-Don, Russian Federation
}

\begin{abstract}
The purpose of this study is to compile an analytical review of the technologies of mass open online courses: their goals, objectives, pedagogical and technical features of the organization in order to use them as an additional educational resource for foreign language teaching of university students. The objectives of the study are to conduct a content analysis, classification and generalization of the results regarding the pedagogical conditions and characteristics of the most representative examples of mass open online courses in the Russian and international segment of educational Internet resources. The research methodology is based on the provisions of the competence-based and personality-oriented approaches to foreign language education at the university. For this purpose, the study examined the organizational and methodological features of the language courses Udemy, Coursera, edX, Stepik, Lectorium, Universarium and some other open education platforms. The analysis made it possible to systematize, summarize and present the main organizational and methodological characteristics of educational platforms in terms of the organization of training and the content of language courses. The study involved 852 students and 14 teachers who used mass open online courses in teaching non-linguistic students a foreign language for two semesters as an additional Internet resource. As a result of the conducted research, the components of the model of using a mass open online course in the organization of distance learning and as an additional training course to the main content of the educational material on the discipline «Foreign Language» at the university were developed and refined.
\end{abstract}

\section{Introduction}

Pedagogy refers to the science of education, involving the design of learning environments and the study of their relative effectiveness. It is also used to define different approaches to teaching and learning, such as constructivist pedagogy $[1,2,3,4]$. Constructivism is a theory that states that learning occurs as a dialogue between prior knowledge and new material. To achieve meaningful learning outcomes, students must «construct» their own concept and

*Corresponding author: kuksa2@gmail.com 
update or revise it, depending on whether their interpretation is correct. A good example would be to apply the scientific method to a situation different from the one in which you studied it. Constructivism is a variant of project-based learning, practice-oriented approaches to learning, and simulation learning are all explored within constructivism. MOOC stands for a Massive Open Online Course. Typically, they include a set of many of the following learning objects: video lectures, online readings, task sets, quizzes, and student interaction. The MOOC aims to reach a much larger audience than traditional courses can accommodate, and to foster interaction between people with similar interests around the world.

Online learning is one of the most important technological breakthroughs in the $21 \mathrm{st}$ century. Online training programs are rapidly evolving in line with the Internet. As part of this development, innovations that were only ideas in the past are now becoming a reality. One of them is the idea-Massive Open Online Courses. MOOCs are built on the dynamic engagement of hundreds of thousands of students who self-organize their participation according to their learning skills, goals, prior knowledge and experience, and common interests. More and more people are participating in the learning process with MOOC courses, as they offer autonomy, energy, and self-regulation to the learners. In general, Internet technologies have created many opportunities for learning and lead to the emergence of various new learning models that evolve and change according to the needs of learning $[5,6,7,8,9,10]$.

MOOC as a term came to the fore in 2008 and is divided into three broad categories:

1) XMOOC-stands for Advanced Mass Open Online Course. These MOOCs are based on traditional university courses. The advantage of HMOs is that they significantly expand the number of students who can be exposed to university-level courses. As a disadvantage, it is pointed out that xMOOCs are inferior to the university courses they mimic, because they are interactive teacher-student interaction and involve limited student-to-student interaction. In general, it can be noted that modern xMOOCs follow a behavioral model of approach to learning.

2) cMOOC-The letter ' $\mathrm{c}$ ' in cMOOC stands for connectivist, which reflects the nature of cMOOC. Stephen Downs, co-founder of one of the first MOOCs, suggested using the term to create a distinction from xMOOC. Instead of being conducted by a teacher, as in traditional university courses, cMOOCs organize groups of people studying together while taking the course. In this environment, all participants are considered teachers and students, which contrasts with the XMOOC structure, where each individual is either a student or a teacher. cMOOCs focus on social interaction, as well as on the participants ' own contribution.

3) SPOC is a small private online course. Unlike MOOCs, SPOCs are a blended learning approach that leverages the capabilities of online platforms in deeper, traditional course settings. The pedagogical experience of Russian and international studies shows that higher education institutions that have initiated the partnership of their own proprietary SPOC with MOOC technologies achieve better learning outcomes.

It should be noted that MOOC technologies increase participation in continuous learning and collaborative methods, provide open, equal, high-quality and free training, and are offered either for personal development or to meet professional needs in accordance with the individual needs of students.

\section{Materials and Methods}

The methodology of the study to compile an analytical review of the technologies of mass open online courses: their goals, objectives, pedagogical and technical features of the organization in order to use them as an additional educational resource for foreign language 
teaching of university students. For this purpose, the study examined the organizational and methodological features of the language courses on such platforms as Udacity, Coursera, EdX, Stepik, Lectorium, Universarium, Open Education. The analysis made it possible to systematize, summarize and present the main organizational and methodological characteristics of educational platforms regarding the organization of study and content of language courses $[11,12]$.

The final component of the electronic educational course for each discipline of the department was an anonymous survey of students in order to assess its quality. $14 \%$ of respondents noted difficulties in completing the course due to a lack of basic language skills. On the other hand, the university always has students who are motivated to study a foreign language deeply. The percentage of such students is quite high. According to the results of our study, it is $62 \%$, which allows the teacher to use the motivational factor in teaching. The survey demonstrated the significant role of the electronic educational course in the formation of competencies necessary for the future profession of university students. $92 \%$ of students have mastered electronic language courses. This suggests that the prospects for using distance learning to eliminate the problems associated with unsatisfactory language training are realized at a sufficient level due to the individualization of training. Thus, language e-learning has proven its stability and ability to overcome difficulties. Foreign language teachers realized in time the need for learning in a remote format using a variety of language education tools [13, 14, 15].

Through all its advantages, the implementation of digital education during foreign language teaching accelerates the assimilation of knowledge. In addition, there is an opportunity to use the time of classroom classes more efficiently [16, 17, 18].

Statistical analysis of the educational content of online language courses allowed us to determine the main educational content, and a survey among university students allowed us to determine the most popular and effective teaching methods for the implementation of an electronic language course.

\section{Results}

The study made it possible to determine the organizational and methodological features of combining the educational content of a mass open online course in a foreign language with didactic materials on the discipline «Foreign Language» at the university, as well as to monitor the learning results using a new, more accurate model of a digital language course for university students.

As a result, the organizational and methodological features of combining the educational content of a mass open online course in a foreign language with didactic materials on the discipline «Foreign language» at the university were listed. The results obtained made it possible to formulate and more effectively apply the main stages of applying a digital course in a foreign language for university students, based on the provisions of a systematic approach to the development of the content of foreign language education and organizational and methodological support for a mass open online course in a foreign language for university students.

The obtained data allowed us to present an experimental model of using a mass open online course in the organization of distance learning and as an additional training course to the main content of the educational material on the discipline «Foreign language» at the university (see Fig. 1). 


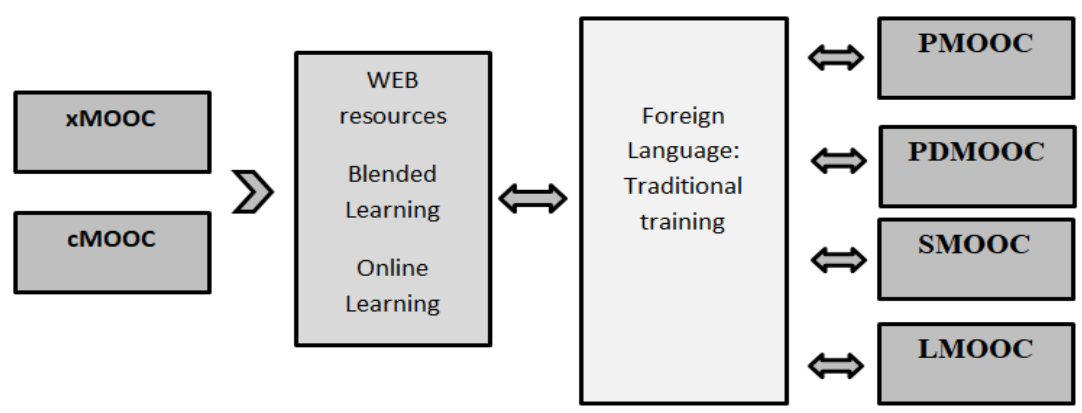

Fig. 1. Model of Integration of MOOC and Traditional Foreign Language Training.

\section{Discussion}

Popular platforms based on xMOOCs are Edx, Coursera, and Udacity. All these features make up the «picture» of traditional learning for xMOOCs, which is distinguished by the presence of video presentations, short quizzes, tests, and knowledge reproduction.

The combination of XMOOC and cMOOC are hybrid environments that combine structured lessons with online communities. Their main features are the mechanisms of support of the trainees from the community and the coach. Learning is delivered through communities that support an interactive and social learning experience, while there is a balance in the structure of the material and the learner's autonomy. All MOOCs can be described as hybrid, as they offer a mix of teaching practices and are created jointly by participants who communicate their personal views, attitudes, and needs.

Hybrid MOOCs are classified, on the one hand, in andragogical, on the other-in socioconstructive learning theory. In addition, they support the structure of the material and control by the coach, social interaction with the coach and the trainees. They provide more freedom in the search for knowledge and attract more active students. Hybrid MOOCs aim to balance the strengths and weaknesses of XMOOC and cMOOC.

Four more types of MOOCs can also be identified as the course design experiments progress:

1. PMOOCs, based on project-based learning projects as well as problem-based learning;

2. PDMOOCs, which include the professional development of people with different careers;

3. SMOOCs that are developed on the basis of social networks (social MOOC) and mobile technologies, while taking ubiquitous approaches to learning.

4. LMOOCs, which include language learning (Language MOOC).

Online educational programs are presented as an ideal environment to meet the needs of modern society and the university community. More specifically, MOOCs provide an ideal learning environment as they are massive, offering the possibility of enrolling a large number of participants and events. In addition, they are open in terms of information sources, curriculum evaluation procedures, and generally in terms of the various learning environments offered to their students. They are often public and free. The courses remain active on the Internet (online courses), so that each participant can access them [19, 20].

Although MOOCs have introduced a new form of distance and online education offering professional development, autonomy, and energy to students, they have nevertheless been criticized for their high development costs and, at the same time, for their 
low completion rates. In addition, the participants of most of the open courses were highly educated specialists.

The MOOC categories (XMOOC, cMOOC, and hybrid MOOCs) are directly related to various learning theories. xMOOCs respond to pedagogical, cognitive-behavioral learning by having pre-defined content that requires the presence of a strong teacher combined with their regular supervision. cMOCs lead to independent learning, the pursuit of connectivity and connectivity through collaboration, communication, and interaction. Finally, hybrid MOOCs are classified in andragogical and specifically in social-constructive learning theory. Its main feature is the provision of support mechanisms for the trainees by the community and the trainer.

MOOCs, unlike simple open courses, allow students participating in them to access all the learning materials of each course from a well-known university. In addition, their students can communicate with their teachers, communicate with their colleagues, exchange opinions, thereby contributing to the management of the MOOC digital classroom, precisely because they are asynchronous educational learning, allowing students, even those living in areas with low quality education, to freely view content and complete their work at any time and in any order they wish. In combination with the above, the population of trainees is heterogeneous in terms of themselves and their intentions. Interns consist of those with a high level of education and full-time employment, but also others without a high school diploma, while they are all committed to the courses and organize their participation according to goals that are flexible and set less strictly, previous knowledge and their common interests. In addition, MOOCs provide the opportunity to attend courses without receiving any certification, credits, honors, or penalty in the event of failure or inability to complete the courses.

At the same time, opportunities for professional development are provided, as employees can enroll in courses related to their careers. In general, MOOCs offer students autonomy, energy, and self-regulation. According to research conducted in the context of MOOCs, they enhance participation in continuing learning and collaborative methods, provide open, equal, quality and free education, and are offered either for personal development or to meet job requirements according to the individual needs of each participant.

The success of the course depends on the individual characteristics of the student and the course parameters, such as the length of time, the required workload, the degree of complexity, and the learning strategy. The latter are influenced by the motivation and confidence of the trainees, the course structure, the environment, the perceptual value of training, the ability to self-regulate, interaction with others, and self-efficacy.

MOOC is an ambitious innovation in the field of education, fully consistent with technological, economic and social development. They use new technologies to offer a wide range of education aimed at a wide audience, covering a wide variety of topics. They apply a variety of teaching methods in an effort to meet the special needs of each student. Although it has not been many years since the first MOOCs appeared, we are seeing their rapid evolution and spread. In this way, MOOCs enhance participation in continuing learning and collaborative methods, provide open, equal, quality and free education, and are offered either for personal development or to meet job requirements according to individual needs. MOOCs are the epitome of the ideal of continuing education, as they offer everyone, without exception, a variety of learning opportunities.

\section{Conclusions}

Thus, in order to improve the quality of foreign language teaching, it is necessary to pay more attention to the development of competencies of all participants in the educational 
process: teachers, students, as well as systematic work on interaction with employers. Such interaction, according to the experience of our research, is effectively carried out by inviting specialists of enterprises to teach individual disciplines. Turning into industrial partners of the university, employers identify the formation of design and professional skills as the most popular competencies for students according to the results of expert interviews. In this regard, curricula should be developed taking into account the requirements of a practice-oriented approach to teaching foreign languages to students of non-linguistic directions. Based on the existing methods used on various distance learning platforms, the developed electronic foreign language training courses allow to improve the quality of foreign language teaching of students and effectively use new opportunities of distance education to increase the creative potential of students. Mastering online courses is an integral part of the process of digitalization of education. With the right approach and the desire to become part of the modern digital world, most teachers and students will gain irreplaceable experience and acquire completely new knowledge in the subject area and in the field of information technology during the implementation of online training.

\section{References}

1. T. Lopatukhina, E. Egorova, V. Sizyakina, Pedagogical management in the virtual information and educational environment of the university, ICERI2020 Proceedings, 2779-2785. IATED, Online Conference (2020).

2. T. Asten, A. Rynkevich, A. Karpova, Technology for distant examinations in a foreign language at a university, ICERI2020 Proceedings, 39-45. IATED, Online Conference (2020).

3. S.V. Pervukhina, G.I. Radchenko, E3S Web of Conferences 210, 18036 1-10 (2020).

4. T.Yu. Sumtsova, O.V. Sumtsova, International Journal of Emerging Technologies in Learning 10 (3), 58-61 (2015).

5. R.S. Adbam, K.O. Lundqvist, European Journal of Open, Distance and e-Learning 1 (18), 123-138 (2015).

6. B.A. Oakley, T.J. Sejnowski, Science of Learning 7 (4), 1-7 (2019).

7. L.M. Alekseeva, Theory and Practice of Modern Professional Education 1, 151-156 (2014).

8. E.N. Ermakova, Chronicles of the United Fund of Electronic Resources Science and Education 53 (10), 12 (2013).

9. T. K. Verenich, S.A. Zlobin, V.S. Srikan, Problems of Modern Education 3, 181-193 (2020).

10. O.V. Kuznetsova, L.P. Halyapina, Modern pedagogical education 3, 131-136 (2019).

11. D.A. Gusev, Science and School 5, 106-112 (2014).

12. K.A. Ummagine, Bulletin of the Moscow State Linguistic University 3 (689), 109-120 (2014).

13. J. Gaida, Library Resources \& Technical Services 3 (62), 149-150 (2018).

14. A.R. Aguilera, R. Griset, F. Santanach, G. Aguado, Digital Educational Material in the Editorial Process of Higher Education Online Courses: a Preliminary Report From an Open Educational Resources Perspective in Mexico and Spain, 4th International Conference on Education and New Learning Technologies (EDULEARN) 1609-1615, Valencia (2012). 
15. P. Hakkarainen, S. Poikela, Practising Information Literacy: Bringing Theories of Learning, Practice and Information Literacy Together 67-94,WaggaWagga: Center Information Studies (2010).

16. O. P. Osipova, Open and distance education 2 (58), 76-82 (2015).

17. V.Yu. Mikhailov, Universum: Psychology and Education 2 (56), 12-14 (2019).

18. E.V. Meshcheryakova, Psychology and Pedagogy: Methods and Problems of Practical Application 36, 116-121 (2014).

19. D.F. Jabborova, Eurasian Union of Scientists 2 (71), 20-22 (2020).

20. I.Yu. Kolpakova, A.A. Moskvitin, Advances in Modern Natural Science 10, 108-109 (2013). 